\title{
Mucous membrane pemphigoid
}

INSERM

\section{Source}

INSERM. (1999). Orphanet: an online rare disease and orphan drug data base. Mucous membrane pemphigoid. ORPHA:46486

Mucous membrane pemphigoid is a bullous dermatosis characterised clinically by blistering of the mucous membranes followed by scarring, and immunologically by $\lg G$, IgA and/or C3 deposits on the epidermal basement membrane. 